\title{
STUDY ON THE ESSENTIALS PARTS OF COOPERATIVE LEARNING
}

\author{
Dr. Sanjay Kumar Yadav* \\ Teacher Education Department, AK COLLEGE Shikohabad, U.P. \\ skyadav1265@gmail.com
}

\begin{abstract}
Over the previous decade, cooperative learning has arisen as the main new way to deal with study hall guidance. One significant justification its support is that various examination concentrates in $\mathrm{K}-12$ study halls, in assorted school settings and across a wide scope of content regions, have uncovered that understudies finishing cooperative learning bunch jobs will in general have higher scholastic grades, higher selfesteem, more prominent quantities of positive social abilities, less generalizations of people of different races or ethnic gatherings, and more noteworthy cognizance of the substance and abilities they are concentrating Furthermore, the viewpoint of understudies functioning as "scholarly introverts" in homerooms is altogether different from that of understudies working cooperatively and cooperatively in and as "cooperative learning scholarly groups" Even with it's anything but, a larger part of the gathering assignments that instructors use, even educators who guarantee to utilize "cooperative learning," keep on being cooperative gathering undertakings not cooperative learning bunch errands. For example, virtually all "jigsaw" exercises are not cooperative learning jigsaw exercises. Just on the grounds that understudies work in little gatherings doesn't imply that they are collaborating to guarantee their own learning and the learning of all others in their This accentuation on scholarly learning accomplishment for every person and all individuals from the gathering is one element that isolates cooperative learning bunches from other gathering undertakings.
\end{abstract}

Keywords: Cooperative Learning, Education, Teaching Pedagogy

\section{INTRODUCTION}

One of the close qualities of a man is the nonstop learning. Just after the birth similar to a youngster one attempt to insinuate the activities and the exercises of the individual who are in close intermediary with the kid. Following a time of birth when child figure out how to talk began asking 'what, why and what about' what he sees which shows up new for him and attempt to acquire data about the exercises and the items around him. As the youngster further grew up he was shipped off school with the goal that he can acquire data and information in various subjects, exercises and fields of life. This is the thing that we call as learning. Wood worth, has characterized it in the structure in a way that would sound natural to him: The learning cycle is such interaction through which reactions and new information can be procured. In brain research the term learning is utilized both as an interaction and as an item for example the term learning is utilized in two structures. Learning as an interaction implies the methodology through which one finds out about new exercises and reality while learning as an item implies the progressions that has been seen in conduct of man because of information one has acquired about new realities and the preparation it get in new exercises. Until and except if learning doesn't impacts change in human conduct it has no importance taking into account therapists. Learning is a constant interaction which rolls out an improvement in human conduct throughout some undefined time frame and that is too in a specific climate. For the viability of learning there are different perspectives which should be dealt with. A portion of these viewpoints are status to learn, requirements of the student, communication with friends and climate, state of learning. 
A portion of the parts of learning measure as clarified above are essential elements for the upgrade of learning. Some among such perspective is peer collaboration. A few educationists and therapists characterize learning as the lasting change in the person's cognizance and purposes. American functionalists (Harvey, Me. Geoch and so forth) clarify the way toward learning through the improvement in execution. As indicated by them, there are however many types of learning as there are models for development. Learning is nonstop cycles which started from the birth onwards and proceed till the demise of an individual and it is learning which rolls out the improvements in the conduct of person.

\section{OBJECTIVES}

1. To think about the mean scholarly accomplishment scores of three gatherings of understudies showed Hindi Grammar with and without utilization of cooperative learning techniques (Students-Teams Achievement Divisions and Team Games Tournaments) before the exploratory treatment.

2. To analyze the mean scholastic accomplishment scores of three gatherings of understudies showed Hindi Grammar with and without utilization of cooperative learning 60 techniques (Students-Teams Achievement Divisions and Team Games Tournaments) after the test treatment.

\section{COOPERATION}

Collaboration in basic terms implies working or acting together for a typical reason. Slavin (1983) characterized collaboration as having four unmistakable segments. The main part is Cooperative Behavior which means working with or helping other people. The subsequent segment is Incentive Structure (Slavin, 1977a) in which dependent fair and square of execution given by the gathering individuals, a gathering is framed comprising of at least two individuals. The third segment is cooperative Task Structure in which a gathering is framed comprising of at least two part however the prize is controlled by the presentation of the entire gathering so the gathering has a likelihood of both having or not having the award. At long last, Cooperation alludes to Cooperative Motives. It involves the pre-assurance to act commonly and conditionally with one another in a circumstance that offers a chance to a person for having a decision between individualistic, cutthroat or cooperative conduct. An educational methodology which gives an individual a shot at "learning to coordinate and collaborating to learning" is known as cooperative learning. It is a kind of homeroom learning climate where combined capacity bunch understudies filled in as one on the scholarly errands. In cooperative learning a little gathering of understudies is completely answerable for the learning of its gathering part just as for his own learning, consequently; cooperative learning is teacher worked with and understudy focused educational procedure. To take care of an issue or to rehearse and procure the topic, the understudies associate with one another in little gatherings. A straightforward definition was offered by Pantiz in which he needs to pass on that instructor has the sole duty of keeping up with the order in the class so that learning climate can be upgraded, cooperation can be organized, and learning action can be planned to engage understudies. Social collaboration construction and learning exercises was planned by the instructor in cooperative learning.

\section{COOPERATIVE LEARNING}

The most generally utilized and compelling procedure of instructing is cooperative learning. "Cooperative learning is perhaps the most suggested instructing learning methods in which understudies accomplish learning objectives by aiding each other in a little group environment. Training itself has been viewed as the social change of a person in a general public. It is more expounded than bunch work movement. It is a fruitful showing system where little groups, each with understudies of various capacities, utilizes an assortment of learning exercises to work on their comprehension of a subject" (Santosh, 2012). Cooperative learning should be applied as a piece of the homeroom the executives framework. Taking all things together or the vast majority of the school 
timetable and educational plan regions, cooperative learning can be underlined. When cooperating with their colleagues or companions, understudies are not kidding achievers. As inside an advisory group, everybody wishes to do something reasonable of work. As a gathering has blended capacity understudies quick students can too gain from the lethargic students.

In cooperative learning individuals needs to figure out how to regard each other's capacities, to coexist with one another so they can unitedly move towards a common objective. Understudy all together can accomplish more that what they accomplish separately. In a council setting student can challenge and propel one another and despite the fact that endeavors are putted down to accomplish shared objectives in instructive undertaking. The gathering in cooperative learning should regard the variety that exists among thoughts and understudies. To reliably accomplish the objectives and thought processes of cooperative learning bunch union is required. To accomplish maximally all requirements to partake effectively In bunch while connecting with peers errands needs to turn out to be clear. Gathering of understudies into little gathering in the homeroom is the fundamental thought behind cooperative learning. Understudies can be assembled into number of ways, for example, by information, by sex or by age. Following at least one of the boundaries referenced over, the study hall in itself appears to have been gathered. As man is basically a social creature its social improvement is must and helpful instructing is one of the major parts of social turn of events. The reliance of its social framework is one of its most significant qualities. In the undertaking of advancement in various stages individuals need assistance of one another. Consequently cooperative learning is a learning method which happens precipitously every one of the occasions in the homeroom.

The Indian study halls are exceptionally heterogeneous in nature. In the study hall, the understudies have various capacities. Some can dominate the subject rapidly and some set aside more effort to accomplish authority. However, the instructor tailors his guidance to the entire gathering without observing heterogeneity of the gathering. Thus, the educating may not be compelling and productive. Thusly, educator should make his guidance more successful and significant, fulfilling the necessities of a wide range of students in the class" In schooling the most broadly explored system of guidance today is cooperative learning. The fundamental component of individual responsibility, bunch handling, positive relationship and communitarian/social abilities are used in all models of cooperative learning. In cooperative learning procedure the part of an educator change before understudies from a teacher to a now facilitator direct and propel the students in friendly domains just as in scholastics. "Cooperative learning may best be characterized as little heterogeneously blended working gathering of students learning social abilities while running after a typical scholarly objective or undertakings" When working in cooperative gatherings, understudies utilizes high request thinking, master important social abilities and practices different ideas, data and cycles. Until and except if there wins certain solid thought and perfectly tuned, cooperative learning can't be effective. "These thought builds the odds that the gatherings will function admirably together and accomplish designated norms." Broad based help from study hall educators and from specialists has been accomplished by cooperative gathering learning throughout the most recent twenty years Accordingly "the recurrence of references to cooperative learning in course books on informative material shows that this way to deal with guidance is appropriate in the instructive standard." Be definition cooperative learning is "the educational utilization of little gatherings, so understudies cooperate to amplify their own and each other's learning; a technique for guidance by which understudies cooperate in little gatherings to arrive at a shared objective; and a movement that works with community endeavors among understudies.

Cooperative learning is a system that advances achievement of gathering individuals and individual understudies, structures proficient and individual relationship and creates sound connection abilities For advancing instructive encounters cooperative learning has different methods that improve understudies to move past customary standard homeroom procedure. The methodology of cooperating in participation "to dominate the material at first introduced by instructor" is cooperative learning. For consummation of gathering task and for fruitful execution of cooperative learning 
procedure all individual from the gathering should make a dominance over the material. A portion of the upsides of cooperative learning system are further developed participation and conduct and expanded preference for school among the understudies Although the majority of the exploration that has been directed so far in regards to cooperative learning technique isn't with essential or grownup kids rather it was finished with more seasoned understudies. Cooperative learning upgrades bunch measures; advances understudy's inspiration, effective gathering support and it encourage scholastic and social connection among understudies in learning of school subjects.

To improve and amplify one's own learning and other's learning in a gathering of understudies so as they will cooperate by utilizing educational methodology is known as cooperative gathering learning. Cooperative learning upgrades better mental change, produces higher accomplishment and positive relationship among understudies than do individualistic encounters. Blossoms and Ritz (1994) saw cooperative gathering learning as a group investigation of at least two who work commonly together to dominate the undertaking of learning. As each student has various capacities every part carries some new capacities to the gathering that might be insightful, concrete or some other capacity. All the colleagues gain from one another and help out their friends for the accomplishment of the errand. It suggests that the ability of the every understudy was united in the gathering and was used for taking care of business. Subsequently, in cooperative learning climate understudies acquire both social abilities and scholarly abilities. "A plan in which understudies are remunerated on premise of the achievement of gathering and understudies works in blended capacity bunch is cooperative learning".

In cooperative learning, to improve and upgrade the comprehension of the subject an assortment of learning strategy was utilized with understudies of various degree of capacities. In cooperative learning an environment of accomplishment is made in which each colleague help their companions as he isn't exclusively dependable of the individual itself yet of his friend bunch part also. "Cooperative learning is a relationship in a gathering of understudies that requires positive association; singular responsibility; relational abilities; vis-à-vis promotive communication and preparing. Every individual from a group is mindful for learning what is educated, yet additionally for aiding colleagues learn, hence making an environment of accomplishment.

\section{ADVANTAGES OF COOPERATIVE LEARNING}

A huge number of studies have been led in India just as in abroad covering different parts of branches of knowledge, capacity levels, social foundation and age bunch. These investigations and the examination custom in field of schooling upheld cooperative learning. The aftereffect of every one of these examination concentrates overall reasoned that cooperative learning upgrades inspiration and friend connection, grows high request thinking and works on relational connections In cooperative gathering learning procedure are allowed to conclude how to realize, who can learn by their own in the gathering subsequently, in this way it improves autonomous learning. In the instructive changes that have been done in Hong Kong the principle accentuation is on 'learning how to learn'. Differentiated capacities of different understudies have been misused by cooperative learning to expand their social and mental presentation and their psychological so students can bargain diversely and viably with the issues of people.

A portion of the unmistakable advantages of receiving cooperative learning perspectives are as per the following:

\section{LEARNING FOR ALL}

In comprehensive study halls sense is made by cooperative gathering learning since it empowers and formalizes association and companion backing and it is expands upon heterogeneity. A few people have the idea that cooperative learning system is useful and is important for kids with inability yet this thought has no pertinence and importance as cooperative learning methodology is helpful for all students including the individuals who have been recognized as talented, in danger, ordinary and bilingual. In climate where necessities of people are tended to and singular strength are perceived is 
best for a student and all understudies needs to work and learn in such climate. To face challenge one should have a sense of security and secure enough consequently students needs to learn and work inside a strong local area.

\section{ACADEMIC ACHIEVEMENT}

While making a correlation among control and test technique for educating with respect to the accomplishment of the understudies it was discovered that understudies have huge higher accomplishment in cooperative learning strategy for instructing instead of customary technique for instructing. For scholarly gains to be available individual responsibility and gathering objectives must be available. The explores that have been done in training upon cooperative learning found that understudies who compromise explained clarification are those which profited most from the exercises. Branches of knowledge are loved by the cooperative learning homeroom understudies than different students. With an intention of performing scholastically well friend standards has been created for cooperative learning.

In cooperative learning thoughts are explained by the understudies through discussion and conversation in this manner basic reasoning is likewise animated. In conventional strategy for educating in conversation the entire class takes part which brings about lower proficiency when contrasted with cooperative learning where in discussion and conversation just at least three part takes part. Inquiries concerning their thoughts and inputs are promptly gotten by the understudies in cooperative learning which assist understudies with planning speedy reactions without hanging tight for long to make a sound conversation. In cooperative learning the material which is being considered during the class, understudies can explain their comprehension of material and ideas and can constantly participate in discussion and conversation. In this manner the information base is built by these understudies all alone. The fundamental concentration in cooperative learning isn't simply comprehension of material by its own yet the idea ought to be cleared so that an understudy can undoubtedly disclose it to their kindred individuals. These further assist understudies with improving the feeling of dependence and vulnerability among understudies to achieve ideas.

\section{ASPECTS OF COOPERATIVE LEARNING}

"Separated cooperative learning from cutthroat and individualistic learning on four bases: objective; level of participation; communication example; and assessment of result as characterized as follows":

Objective: In cooperative learning individual are relegated to heterogeneous gathering comprising of little part little gathering and this gathering is given the guidance to (a) to dominate the material which was doled out to them and (b) all gathering part need to guarantee that they perform moreover.

Level of Cooperation: to the entire class the participation was expanded (the educator needs to guarantee that the doled out material ought to be learned by everybody) and the school (one needs to guarantee that all individuals should advance scholastically in the school) levels.

Cooperation Pattern: class individuals advance and empower accomplishment of each other's. In cooperation design peer individuals connect with one another the material allocated to them, instructor will clarify the strategy for finishing the example of task, peer individuals need to advance the difficult work of one another, give scholarly assistance and help and pay attention to one another's clarification. There exists a connection design inside bunch just as in the middle.

Assessment of Outcomes: An assessment and evaluation framework comprising of rules reference is utilized; the primary thought process of cooperative learning is scholastic advancement and learning of all people which incorporate the school, the class and the gathering in general. 


\section{SUPERIORITY OF COOPERATIVE LEARNING}

1. Prima-facie, the four basic postulates of the learning process including:

2. The learning methodology, particularly the cooperative learning procedure;

3. The learning results, as far as execution accomplishment;

4. Interpersonal relationship, involving the entirety of human relations as determinants of solid school environment; and

5. self-regard as the chief human trademark go far in esteem teaching, for example, selfcertainty or self-worth pertinent to the strength of human conduct and sanction development, the hidden extreme objective of instruction fundamentally.

The discoveries do demonstrate the predominance of the cooperative learning procedure over the customary study hall showing measures, which for sure has been the developing interest of the fun loving undertaking for all commonsense motivation behind reasonable turn of events and blissful learning, particularly at the grade school level. The outcomes in any case, don't, in any capacity, dispose of or sabotage the significance of individualized learning procedures, nor was it the goal. It just shows that the procedure of cooperative learning is considerably more pivotal to the teaching of upsides of cooperative living and sound participation instead of the dry bones of sheer contest that thin downs the cycle of training to self-coordinate individualized learning. Fundamentally, both sound participation just as solid rivalry supplement and supplement each other in making the learning cycle substantial to supportable human turn of events. Consequently, the two of them are compulsory by their own doing to successful tutoring.

\section{RELEVANCE OF COOPERATIVE LEARNING}

Deciphered with regards to worldwide points of view of schooling throughout the long term, the discoveries appear to be essentially applicable. UNESCO's two milestone commitments to the reason for schooling in particular, Edgar Faure's Report, 'LEARNING TO BE: The World of Education Today and Tomorrow' (1972), and Jaques Delors Report, 'LEARNING: THE TREASURE WITHIN' (1996), clearing the guide for instruction in the 21st century, giving a vigorous way of thinking of deep rooted cooperative learning to fastidiously address the difficulties of another world request through the cycle of training. In like manner, school training should focus on all-around improvement of a youngster's character modifying it around the 'FOUR PILLARS OF EDUCATION'- Learning to Know, Learning to Do; Learning to Be; and Learning to Live Together-as commonly comprehensive for agreeable, feasible and healthy advancement of instruction. It recommends 'Learning to Learn with Love' involving moment readiness to learn, innate capacity to stay centered combined with collaboration and a sound feeling of rivalry to accomplish the learning result through hearty connections and keeping up with, selfrespect as a noteworthy ethicalness. As such, 'Learning to Know' not just covers the entire intellectual area of information yet additionally the techniques of knowing. Additionally, 'Learning to Do' recommends the entire space of activity and the procedures of tackling one's assignment handily while 'Learning to $\mathrm{Be}^{\prime}$ involves the entire area of qualities and full of feeling learning and the connected methods, including relational connections also. Furthermore, in the last investigation, 'Learning to Live Together' not just addresses the entire range of cooperative learning yet in addition of how to go about as far as strategies included.

Basically, the consequences of the examination close by contrasts well and the UNESCO's point of view on instructive advancement for the 21st century, particularly in building a learning society towards creating and setting up harmony and congruity on the planet request through 'Learning to Learn with Love' and 'Learning to Live Together' as the indispensable strength of cooperative learning. The discoveries consequently have fundamental significance for training, its interaction and systems. 


\section{COOPERATIVE LEARNING AND SELF CONCEPT}

Cooperative learning has different mental results and generally significant among them is their impact on self idea of understudies. In limited capacity to focus season of the research center examination, the adjustment of the self idea that has shown up with time can't be estimated as it must be estimated over long haul term tests. Coppersmith in his examination shows the self idea in school going youngsters. In peer gatherings and in school, other are exceptionally affected that understudies are performing admirably. Discovered "beneficial outcomes of Jigsaw on understudies self idea in light of its utilization of individualized guidelines, where understudies can be effective working at their own". Self idea if there should arise an occurrence of math have solid impacts was when finished with TAI technique for cooperative learning. Adams in 1995 researched "the viability of cooperative learning strategy, STAD on accomplishment and self regard level somewhat incapacitated and 64 ordinary advancing students of 6 th grade. The treatment bunch had fundamentally more elevated levels of scholastic accomplishment in understanding cognizance; they had essentially more significant levels of self regard, however didn't contrast in school and scholarly self regard". Scholastics the individuals who work upon cooperative learning likewise centered on self idea and social insight to further develop them to more prominent quality. The examination that has been directed over the course of the year shows that as if there should be an occurrence of scholastic accomplishment in understudies, cooperative learning strategy likewise improves self proficiency, self idea and self regard among the understudies at various levels and in various subjects.

\section{CONCLUSION}

The discoveries of the examination presumed that while concerning the two trial gatherings of cooperative learning that trial bunch 1 and exploratory gathering 2, both the gatherings of understudies were shown Hindi Grammar through cooperative learning strategy yet both of these gatherings have utilized the distinctive technique. Exploratory gathering 1 was instructed through Team Games Tournament and the trial bunch 2 was educated through Students-Team Achievement Division. While concerning scholastic accomplishment of the understudies both these strategies end up being similarly proficient. The post hoc table uncovers that there is distinction between the benchmark group and the trial bunch yet the contrast between the test bunch 1 and test bunch 2 isn't huge. Henceforth, both Team Games Tournament and Students-Team Achievement Division helped in expanding the scholarly accomplishment of the understudies.

\section{REFERENCE}

[1]. Adams, E.R.(2012). The effects of cooperative learning on the achievement and self-esteem levels of students in the inclusive classroom. Dissertation Abstracts International56/05,P.1741.

[2]. Ahuja, A.(2013). The effects of a cooperative learning instructional strategy on the academic achievement attitudes towards science class and process skills of middle school science students. Dissertation Abstracts International-A55/10,P.3149.

[3]. Anderson, D., Johnson, D.W., Johnson, J., \& Johnson R.T.(2015). Effects of cooperative versus individualized instruction on student pro-social behavior, attitudes toward learning and achievement. Journal of Educational Psychology,68(4),446-452.

[4]. Parker, R. (2014). Small-group cooperative learning. The Education Digest, 51, 44-46.

[5]. Sharan, S. \& Hertz-Lazarowitz, R. (2013). A group investigation method of cooperative learning in the classroom. In S. Sharon (Ed.), Cooperation in Education. Provo, UT: Brigham Young University Press

[6]. Slavin, R. (2013). Student teams and achievement divisions. Journal of Research and Development in Education, 12, 39-49.

[7]. Slavin, R. (1981). Synthesis of research on cooperative learning. Educational Leadership, 38(8), 655-660. 
[8]. Slavin, R. (2014). Students motivating students to excel: Cooperative incentives, cooperative tasks, and student achievement. The Elementary School Journal, 85(1), 53--63.

[9]. Slavin, R. (2015). Using Student Team Learning (3rd ed.). Baltimore: Johns Hopkins University Press.

[10]. Webb, N. (2015). Student interaction and learning in small groups: A research summary. In R. Slavin, S. Sharan, S. Kagan, R. Hertz-Lazarowitz, C. Webb \& R. Schmuck (Eds.), Learning to cooperate, cooperating to learn. New York: Plenum.

\begin{tabular}{|l|l|}
\hline \multicolumn{2}{|c|}{ Editorial Processing Record } \\
\hline Date of Submission: & $21-$ Oct-2021 \\
\hline Date of Final Review: & $26-$ Nov-2021 \\
\hline Date of Acceptance: & $02-$ Dec-2021 \\
\hline Final Processing: & $26-$ Dec-2021 \\
\hline Date of Publishing: & 29-Dec-2021 \\
\hline \multicolumn{2}{|c|}{ Last Plagiarism Report } \\
\hline \multicolumn{2}{|c|}{ Overall Similarity: } \\
Dinality Assessment \\
Statistics: 133 words Plagiarized / 4309 Total words \\
Remarks: Low similarity detected, check your supervisor if changes are required
\end{tabular}

